\title{
Flora
}

\section{Scutellaria caucasica A. Ham.: morphological features and headspace characterization --Manuscript Draft--}

\begin{tabular}{|c|c|}
\hline \multicolumn{2}{|l|}{ Manuscript Number: } \\
\hline Article Type: & Research Paper \\
\hline Keywords: & $\begin{array}{l}\text { Scutellaria caucasica A. Ham.; Glandular trichomes; Microscopy; VOC profile; HS- } \\
\text { SPME }\end{array}$ \\
\hline Corresponding Author: & $\begin{array}{l}\text { Martina Bottoni } \\
\text { Universita degli Studi di Milano } \\
\text { Milano, MI ITALY }\end{array}$ \\
\hline First Author: & Claudia Giuliani, Dr. \\
\hline \multirow[t]{6}{*}{ Order of Authors: } & Claudia Giuliani, Dr. \\
\hline & Martina Bottoni \\
\hline & Roberta Ascrizzi, Dr. \\
\hline & Fabrizia Milani, Dr. \\
\hline & Guido Flamini, Prof. \\
\hline & Gelsomina Fico, Prof. \\
\hline Abstract: & 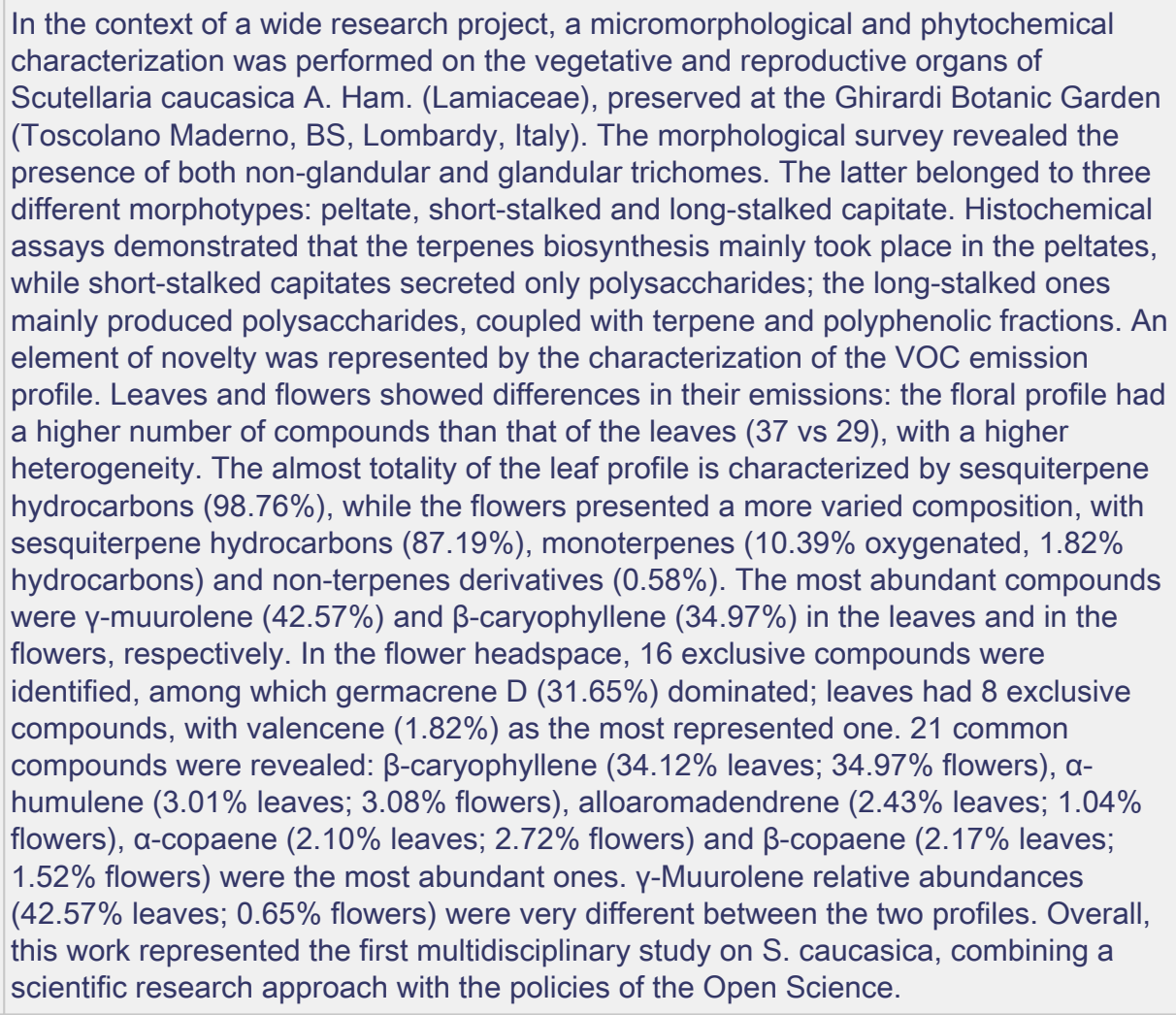 \\
\hline \multirow[t]{3}{*}{ Suggested Reviewers: } & $\begin{array}{l}\text { Ammar Bader } \\
\text { Umm Al-Qura University } \\
\text { ammarosio@yahoo.it }\end{array}$ \\
\hline & $\begin{array}{l}\text { Filippo Maggi } \\
\text { Universita degli Studi di Camerino } \\
\text { filippo.maggi@unicam.it }\end{array}$ \\
\hline & $\begin{array}{l}\text { Lia Ascensao } \\
\text { University of Lisbon } \\
\text { lia.ascensao@fc.ul.pt }\end{array}$ \\
\hline
\end{tabular}




\section{Opposed Reviewers:}

Powered by Editorial Manager ${ }^{\circledR}$ and ProduXion Manager ${ }^{\circledR}$ from Aries Systems Corporation 


\section{Highlights}

- A multidisciplinary study approach was adopted for S. caucasica A. Ham.

- Morphological, histochemical and phytochemical investigations were performed.

- Three trichome morphotypes formed the glandular indumentum of leaves and flowers.

- The VOC profiles of leaves and flowers were characterized for the first time. 


\section{Scutellaria caucasica A. Ham.: morphological features and headspace}

2 characterization

3 Claudia Giuliani a,b, Martina Bottoni a,b, ${ }^{*}$, Roberta Ascrizzi c, Fabrizia Milani a,b, Guido Flamini c,

4 Gelsomina Fico a,b

5 aDepartment of Pharmaceutical Sciences, University of Milan, Via Mangiagalli 25, I-20133 Milan, Italy;

6 bGhirardi Botanic Garden, Department of Pharmaceutical Sciences, University of Milan, Via Religione 25,

7 I-25088 Toscolano Maderno, Brescia, Italy; 'Department of Pharmacy, University of Pisa, Via Bonanno 6,

8 I-56126 Pisa, Italy;

9

Authors' e-mail addresses: claudia.giuliani@unimi.it; martina.bottoni@unimi.it; roberta.ascrizzi@gmail.com; fabriziamilani.90@gmail.com; ; guido.flamini@unipi.it; gelsomina.fico@unimi.it

${ }^{*}$ Corresponding author: Dr. Martina Bottoni, Department of Pharmaceutical Sciences, 


\section{Abstract}

In the context of a wide research project, a micromorphological and phytochemical characterization was performed on the vegetative and reproductive organs of Scutellaria caucasica A. Ham. (Lamiaceae), preserved at the Ghirardi Botanic Garden (Toscolano Maderno, BS, Lombardy, Italy). The morphological survey revealed the presence of both non-glandular and glandular trichomes. The latter belonged to three different morphotypes: peltate, shortstalked and long-stalked capitate. Histochemical assays demonstrated that the terpenes biosynthesis mainly took place in the peltates, while short-stalked capitates secreted only polysaccharides; the long-stalked ones mainly produced polysaccharides, coupled with terpene and polyphenolic fractions. An element of novelty was represented by the characterization of the VOC emission profile. Leaves and flowers showed differences in their emissions: the floral profile had a higher number of compounds than that of the leaves (37 vs 29), with a higher heterogeneity. The almost totality of the leaf profile is characterized by sesquiterpene hydrocarbons (98.76\%), while the flowers presented a more varied composition, with sesquiterpene hydrocarbons (87.19\%), monoterpenes (10.39\% oxygenated, $1.82 \%$ hydrocarbons) and non-terpenes derivatives (0.58\%). The most abundant compounds were $\gamma^{-}$ muurolene $(42.57 \%)$ and $\beta$-caryophyllene $(34.97 \%)$ in the leaves and in the flowers, respectively. In the flower headspace, 16 exclusive compounds were identified, among which germacrene D (31.65\%) dominated; leaves had 8 exclusive compounds, with valencene $(1.82 \%)$ as the most represented one. 21 common compounds were revealed: $\beta$-caryophyllene (34.12\% leaves; $34.97 \%$ flowers), a-humulene (3.01\% leaves; 3.08\% flowers), alloaromadendrene ( $2.43 \%$ leaves; $1.04 \%$ flowers), a-copaene ( $2.10 \%$ leaves; $2.72 \%$ flowers) and $\beta$-copaene $(2.17 \%$ leaves; $1.52 \%$ flowers) were the most abundant ones. $\gamma$-Muurolene relative abundances ( $42.57 \%$ leaves; $0.65 \%$ flowers) were very different between the two profiles.

Overall, this work represented the first multidisciplinary study on S. caucasica, combining a scientific research approach with the policies of the Open Science.

\section{Keywords}

Scutellaria caucasica A. Ham., Glandular trichomes, Microscopy, VOC profile, HS-SPME. 
The family Lamiaceae is widespread worldwide and includes 252 genera and 6800 species (Judd et al., 2009; De Oliveira et al., 2013). Due to their pleasant fragrances, produced in the glandular trichomes, many species are used in the herbal, food and cosmetic sectors (Akçin et al., 2011) and are widely employed in the folk medicine and as ornamentals (Baytop, 1999; Özdemir and Şenel, 2001).

Scutellaria L., or Skullcap, is a genus comprising about 350 species with a cosmopolitan distribution (Paton, 1990; Pool, 2006) and mainly found in the temperate areas. An important centre of diversity is represented by the Eurasian region (Minareci and Pekönür, 2017). The term Skullcap refers to a peculiar scale-shaped appendage of the calyx, called scutellum, which is formed by the folding of the upper lip and which comes off before fruiting (Paton, 1990; Minareci and Pekönür, 2017).

Scutellaria caucasica A. Ham. is an herbaceous plant native to the North Caucasus. It has sturdy stems, slightly curved, $10-32 \mathrm{~cm}$ long; green leaves, $0.8-3 \mathrm{~cm}$ long and $0.3-1.5 \mathrm{~cm}$ wide, ovate-oblong in shape with dentate margins; sturdy petiole, $0.2-2 \mathrm{~cm}$ long. It blooms in May-August and shows inflorescences from $3.5 \mathrm{~cm}$ to $6 \mathrm{~cm}$ long, elongated-ovoid or conical and dense; large and ovate bracts with entire margins; calyx $3 \mathrm{~mm}$ long; large corolla, from 3 to $3.5 \mathrm{~cm}$ long and $8 \mathrm{~mm}$ wide at throat, yellow in colour, with lips approximately equal in length. The whole plant surface is characterized by the presence of trichomes (Komarov, 1976).

In Asia, Europe and America, many species of Scutellaria are used as remedies in traditional medicine (Shang et al., 2010; Sripathi et al., 2017). For example, S. orientalis L. is used in case of constipation, as haemostatic, tonic and in wounds treatment in Anatolia (Yilmaz et al., 2019), S. baicalensis Georgi, thanks to the beneficial properties of its root, has been included in the Chinese, Japanese, Korean and European Pharmacopeia (Kosakowska, 2017) and S. altissima L. is a well-known plant in the Traditional Chinese Medicine, useful for the treatment of respiratory infections, pneumonia, bronchitis and in cases of hypertension (Bozov and Coll, 2015; Grzegorczyk-Karolak et al., 2016; Gao et al., 2017;), hepatitis and cancer (Li and Wei, 1994; Malakov and Papanove 1996; Sripathi and Ravi 2017). S. caucasica A. Ham. is known in the traditional American medicine against viral infections ( $\mathrm{Li}$ et al., 2000). In addition, different uses are described for Scutellaria species coming from other regions of the World (Kosakowska 2017; Sripathi et al., 2017; Irvin et al. 2019).

The commercial interest of the Lamiaceae is mainly related to the presence of glandular trichomes (Werker, 2006), responsible for the synthesis of natural bioactive compounds that display a crucial ecological role (Maffei, 2010; Giuliani et al., 2017a; Giuliani et al., 2017b; Giuliani et al., 2018). The literature proposed several morphological studies focused on the glandular indumentum of species belonging to Scutellaria (Giuliani and Maleci Bini, 2008; 
Dereboylu et al., 2012; De Oliveira et al., 2013; Cali, 2017a, 2017b; Giuliani et al., Unpublished results (a), (b)), however none of them referred to $S$. caucasica.

Concerning the phytochemical state of the art, previous works on congeneric species reported the analysis of the essential oil composition (Rosselli et al., 2007; Cicek et al., 2011; Formisano et al., 2013; Kurkcuoglu et al., 2019; Yilmaz et al., 2019) and the characterization of the profiles of the volatile organic compounds (VOCs) (Takeoka et al., 2008, 2009; Giuliani et al., Unpublished results (a), (b)). Nevertheless, similar studies are lacking for S. caucasica, since the existing phytochemical literature only reported the isolation and NMR characterization of diterpenes (De La Torre et al., 1997; Bruno et al., 2000) and the isolation of typical flavonoids (Bandyukova and Boikova, 1969).

Regarding the biological activity, no published study is reported about this species. On the contrary, studies were conducted on the pharmacological activity of some compounds isolated from congeneric species (Irvin et al., 2019).

This work is part of a wider project entitled "Botanic Garden, factory of molecules", recently financed by the Lombardy Region (Italy). The primary goal of the project is to investigate a selected pool of species preserved at the Ghirardi Botanic Garden (Toscolano Maderno, BS, Lombardy, Italy), including S. caucasica, in order to: 1. describe the morphological features and the distribution pattern of the glandular trichomes observed on the vegetative and reproductive organs by means of light and scanning electron microscopy; 2. characterize the secretion products through histochemical tests; 3 . correlate the micromorphological investigation of the secreting structures with the productivity in secondary metabolites through the phytochemical characterization of VOCs spontaneously emitted by leaves and flowers. These results, along with those obtained by our research group in previous investigations on congeneric species, i.e. S. brevibracteata subsp. subvelutina (Giuliani et al., Unpublished results (a)) and S. altissima (Giuliani et al., Unpublished results (b)), will flow into the realization of novel iconographic devices devoted to the visitors of the Garden. In this way, the generic public will be able to learn updated details of the scientific research in an Open Science contest.

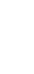




\section{Materials and Methods}

\subsection{Plant material}

Scutellaria caucasica A. Ham. was cultivated at the Ghirardi Botanic Garden (Toscolano Maderno, BS, Lombardy, Italy) of the Department of Pharmaceutical Sciences of the University of Milan. Samplings were performed in June 2019. The samples were used for both the morphological and the phytochemical surveys on the vegetative and the reproductive organs. Voucher specimens were deposited in the Herbarium of the Ghirardi Botanic Garden under the identification codes GBG2019/016 and GBG2019/017.

\subsection{Micromorphological survey}

This survey was carried out in order to characterize the glandular and non-glandular indumentum, the distribution pattern of the trichomes and to evaluate the chemical nature of the secreted material using scanning electron microscopy (SEM) and light microscopy (LM). Various histochemical techniques were used to better locate the sites of synthesis and storage of the secondary metabolites, with special focus on volatiles.

\subsubsection{Scanning Electron Microscopy (SEM)}

Plant material was firstly hand-prepared, by fixing it in $2.5 \%$ glutaraldehyde in phosphate buffer (0.1 M, pH 6.8). Then, it was dehydrated in an ascending ethanol series up to absolute and then dried using a critical point dryer apparatus. The samples, previously mounting on aluminium stubs, were coated with gold and examined with a Philips XL 20 SEM operating at $10 \mathrm{kV}$.

\subsubsection{Light Microscopy (LM)}

Fresh and fixed samples were prepared. Fresh material was frozen and cryo-sectioned; other samples were fixed in FAA solution (formaldehyde:acetic acid: ethanol 70\% = 5:5:90) for 7 days, dehydrated in ascending ethanol series up to absolute, embedded in Technovit/Historesin and sectioned with an ultramicrotome. The following histochemical stainings were employed: Fluoral Yellow-088 for total lipids (Brundett et al., 1991), Nile Red for neutral lipids (Greenspan et al., 1985), Nadi reagent for terpenes (David and Carde, 1964), Ruthenium Red for acid polysaccharides (Jensen, 1962), Alcian Blue for mucopolysaccharides (Beccari and Mazzi, 1966), and Ferric Trichloride for polyphenols (Gahan, 1984). Control tests were performed at the same time. Observations were made with a Leitz DM-RB Fluo optical microscope.

\subsection{Phytochemistry}

\subsubsection{Volatile Organic Compounds (VOCs)}

Three leaves and three flowers were cut and immediately inserted into separate glass vials of suitable volume for the analysis.

HS-SPME Sample analysis - The headspace sampling conditions were as reported in Ascrizzi et al. (2017). For the headspace samplings, Supelco SPME (Solid Phase Micro-Extraction) devices, 
181 coated with polydimethylsiloxane (PDMS, $100 \mu \mathrm{m}$ ) were used; the same new fibre,

182 preconditioned according to the manufacturer instructions, was employed for all the analyses.

183 To ensure a stable temperature, samplings were conducted in an air-conditioned room at $22 \pm$ $1841^{\circ} \mathrm{C}$; this temperature was chosen to avoid the thermal damage of the plant material and, 185 thus, any artificial-induced volatiles release. After $30 \mathrm{~min}$ of equilibration, the fibre was 186 exposed to sample the headspace for $30 \mathrm{~min}$. Both the equilibration and sampling times were experimentally determined to obtain an optimal adsorption of the volatiles, and to avoid both under- and over-saturation of the fibre and of the mass spectrometer ion trap. Once sampling was finished, the fibre was withdrawn into the needle and transferred to the injection port of the GC-MS system. Both the sampling and desorption conditions were identical for all the samples. Furthermore, blanks were performed before each first SPME extraction and randomly repeated during each series. Quantitative comparisons of relative peaks areas were performed between the same compounds in the different samples.

194

195

196

197

198

199 
The indumentum of the vegetative and reproductive organs of S. caucasica showed both glandular and non-glandular trichomes on the overall epidermal surfaces (Table 1, Figures 1 capitate (Fig. 1). The distribution pattern and abundance on the investigated plant parts are shown in Table 1.

The peltate trichome (Figure 1 a) occurred on both the leaf surfaces (Table 1, Figures 1 df) and on the abaxial sides of the bracts, calyx and corolla (Table 1, Figures $1 \mathbf{~ g , ~ i , ~ k ) . ~ T h i s ~}$ morphotype consisted of a basal cell, a neck cell and a multicellular head surrounded by a wide storing chamber. Two types of capitate trichomes were observed: short-stalked and longstalked capitate (Figures $\mathbf{1} \mathbf{a}-\mathbf{c}$ ). The former were very abundant and scattered on the whole plant (Table 1, Figure $\mathbf{1} \mathbf{f}, \mathbf{g}, \mathbf{i}, \mathbf{k}$ ) and consisted of a basal cell, a stalk cell and a 2-4 celled head.

The long capitates, only present on the inflorescences, particularly on the abaxial surfaces of sepals and petals (Table 1, Figures $\mathbf{1}$ g-i, I), possessed a multicellular head (5-6 cells) with a median, small subcuticular space (Figures $\mathbf{1} \mathbf{b}, \mathbf{c}, \mathbf{h}$ ); the length of the stalk resulted variable. The secretion was firstly accumulated in the subcuticular spaces and then flowed out along the stalk. The non-glandular hairs were multicellular, uniseriate, with acute apices; they were ubiquitous and their length was variable ranging from 1-2 cells on stems, leaves and bracts up to 5-7 cells on the abaxial side of calyx and corolla (Figure 1 a-I).

\subsubsection{Histochemistry of the glandular trichomes}

The results of the histochemical investigation are reported in Table $\mathbf{2}$ and Figure 2. The peltates secretion proved positive only to stainings specific for lipophilic substances, showing in particular an intense positive response to Nadi reagent (Table 2, Figure $\mathbf{2}$ a), indicating the peculiar secretion of terpenes. The histochemical stainings indicated the exclusive production of acid polysaccharides (Table 2, Figure $\mathbf{2}$ b) for the short-stalked capitate morphotype. The histochemical assays on the long-stalked capitate showed mainly polysaccharidic with terpenic and polyphenolic fractions (Table 2, Figures 2 c-e). 


\subsection{Phytochemical investigation}

250

\subsubsection{VOCs emission profile}

The VOC emission profile of S. caucasica revealed a total of 45 different compounds. 29 compounds were identified in the foliar profile, while 37 in the floral one (Table $\mathbf{3}$ ).

The sesquiterpene hydrocarbons accounted for almost the totality of the leaf profile $(98.76 \%)$, followed by the oxygenated sesquiterpenes (0.90\%). Monoterpenes and non-terpene derivatives were not detected. $\gamma$-Muurolene $(33,42.57 \%)$ dominated, followed by $\beta$ caryophyllene $(22,34.12 \%)$. Among all the other compounds, only a-humulene $(29,3.01 \%)$, alloaromadendrene $(31,2.43 \%), \beta$-copaene $(23,2.17 \%)$ and a-copaene $(17,2.10 \%)$ exhibited relative concentrations higher than $2 \%$. Eight exclusive compounds were characterized, among which valencene $(36,1.82 \%)$ was the most abundant one. The other exclusive compounds were present in percentages lower than $1.0 \%$ or in traces.

The floral profile was dominated by the sesquiterpene hydrocarbons ( $87.19 \%)$, followed by oxygenated monoterpenes (10.39\%), monoterpene hydrocarbons (1.82\%) and non-terpene derivatives $(0.58 \%)$. Oxygenated sesquiterpenes were not detected. The most abundant compound was $\beta$-caryophyllene $(22,34.97 \%)$, followed by germacrene D $(34,31.65 \%), 1,8$ cineole $(3,8.00 \%)$, a-humulene $(29,3.08 \%)$, bicyclogermacrene $(37,2.89 \%)$ and a-copaene $(17,2.72 \%)$. The other compounds were present with relative amounts lower than $2.0 \% .16$ exclusive compounds were identified, among which the above-mentioned major compounds $(34,3,37)$. The others occurred with relative abundances lower than $2.0 \%$.

21 common compounds were detected. The compounds found in higher relative contents in both the organs were $\beta$-caryophyllene (22, 34.12\% leaves; $34.97 \%$ flowers), followed by ahumulene (29, 3.01\% leaves; $3.08 \%$ flowers), alloaromadendrene $(31,2.43 \%$ leaves; $1.04 \%$ flowers), a-copaene $(17,2.10 \%$ leaves; $2.72 \%$ flowers $)$ and $\beta$-copaene $(23,2.17 \%$ leaves; $1.52 \%$ flowers). $Y$-Muurolene (33) displayed a higher relative abundance in the leaves $(42.57 \%)$ than in the flowers $(0.65 \%)$. A similar pattern, with less noticeable differences in relative abundance, was found for $\beta$-cubebene $(19,1.28 \%$ leaves; $0.66 \%$ flowers $)$ and cismuurola-4(14),5-diene (32, 1.31\% leaves; $0.91 \%$ flowers). The remaining common compounds showed comparable percentages in the two profiles $(<2.0 \%)$. 
283 The indumentum of the vegetative and reproductive organs of $S$. caucasica showed a high level of consistency for both morphology and distribution pattern in all the examined replicates. The glandular trichomes were numerous and belonged to the two main types occurring in the family Lamiaceae: peltate and capitate (Werker, 2006; Giuliani et al., 2017a, Giuliani et al., 2018). The peltate ones occurred on both the vegetative and reproductive organs, as documented in other Scutellaria species (Giuliani and Maleci Bini, 2008; Dereboylu et al., 2012; De Oliveira et al., 2013; Giuliani et al., Unpublished results (a), (b)). The capitate morphotype was distinguished in short-stalked and long-stalked capitate, already described in other works on congeneric species (Giuliani and Maleci Bini, 2008; Giuliani et al., Unpublished results (a), (b)) and presented a different distribution pattern. The short-stalked capitates, widespread in all the members of the Lamiaceae family (Hallahan, 2000), were evenly distributed on the entire epidermal surface of the plant and were particularly abundant on the abaxial surfaces of the leaves and corolla. On the contrary, the long-stalked capitates were typical of the reproductive organs, as described in several members of the Lamioideae subfamily (Giuliani and Maleci Bini, 2008) and as already documented by our research group in S. brevibracteata subsp. subvelutina and S. altissima (Giuliani et al., Unpublished results (a), (b)). The histochemical tests were performed to localize in situ the main compound classes of metabolites present in plant secretions and were widely used to accurately describe the glandular trichomes of many Lamiaceae species (Giuliani and Maleci Bini, 2008; Giuliani et al., Unpublished results (a), (b)). As regards to the composition of the secreted material, each trichome type was generally characterized by a single or by a prevailing kind of secretion, as already reported in devoted reviews by Hallahan (2000) and Werker (2000) (see literature therein). Peltate trichomes are generally considered typical producers of terpenes; capitate trichomes produce generally a more complex secretion of both hydrophilic and lipophilic fractions, in which polysaccharides prevail. In S. caucasica, the composition of the secreted material was clearly related to the trichome type. Indeed, the histochemical tests revealed that the peltate hairs were the main sites of production and accumulation of terpenes, in consistency with the results on S. altissima (Giuliani et al., Unpublished results (b)). On the contrary, in S. brevibracteata subsp. subvelutina the secretion product of the peltates appeared more complex because of the contemporary synthesis of polyphenols and flavonoids (Giuliani et al., Unpublished results (a)). The short capitates were exclusive polysaccharide producers, as well as in S. altissima and S. brevibracteata subsp. subvelutina (Giuliani et al., Unpublished results (a), (b)). The long capitate exhibited, as in the two congeneric species, a more complex secretion of both hydrophilic and lipophilic substances, in which terpenes represent a minor fraction. Therefore, it can be postulated that in S. caucasica the productivity in volatile substances depended exclusively on the peltates on stems, leaves and bracts and on the synergistic action of peltates and long capitates on calyces and corollas. However, given 
the greater productivity of the peltates compared to that of the long-stalked capitates, a feature that can be directly correlated to the presence of a wider storing chamber in the former, the peltates were confirmed as the main producers of terpenes on the reproductive organs.

324 Concerning the phytochemical survey, the characterization of the VOC emission profiles represents an element of novelty for S. caucasica. A high level of variability was recorded between leaves and flowers. In fact, the latter presented a higher number of compounds compared to the former ( 37 vs 29) and exhibited greater heterogeneity in the compound classes. Indeed, the floral profile showed the presence of sesquiterpenes (hydrocarbons $87.19 \%$ ), monoterpenes (oxygenated $10.39 \%$; hydrocarbons $1.82 \%$ ) and non-terpene substances $(0.58 \%)$. On the contrary, the leaves only emitted sesquiterpenes, with a clear preponderance of hydrocarbons (98.76\%) over oxygenated derivatives $(0.90 \%)$. Another distinctive element was represented by the principal compounds: the foliar profile presented $\mathrm{Y}^{-}$ muurolene $(33,42.57 \%)$ and $\beta$-caryophyllene $(22,34.12 \%)$ as the most abundant compounds, while the floral profile had $\beta$-caryophyllene $(22,34.97 \%)$ and germacrene $D(34$, $31.65 \%$ ) as the most represented ones. Germacrene D (34) and $y$-muurolene (33) can be considered the representative compounds of the two profiles: the former was absent in the leaves, while the latter showed scarce abundance in the flowers $(0.65 \%)$. Moreover, the flowers had a number of exclusive compounds twice as many those of the leaves (16 vs 8). Among the former, germacrene $\mathrm{D}(34,31.65 \%), 1,8$-cineole $(3,8.00 \%)$ and bicyclogermacrene $(37,2.89 \%)$ dominated, among the latter valencene $(36,1.82 \%)$. Twentyone common compounds were identified: $\beta$-caryophyllene $(22,34.12 \%$ leaves; $34.97 \%$ flowers) was the most abundant one, followed by a-humulene $(29,3.01 \%$ leaves; $3.08 \%$ flowers), alloaromadendrene (31, 2.43\% leaves; $1.04 \%$ flowers), a-copaene $(17,2.10 \%$ leaves; $2.72 \%$ flowers $)$ and $\beta$-copaene $(23,2.17 \%$ leaves; $1.52 \%$ flowers $)$. Making a comparison with previous investigations, a higher degree of homogeneity was shown compared to the S. brevibracteata subsp. subvelutina volatile emission profiles: the floral profile was more complex than the foliar one; sesquiterpenes hydrocarbons was the representative compound class in both profiles; $\beta$-caryophyllene was the most abundant compound both in leaves and flowers. Conversely, concerning these aspects, S. altissima presented a foliar profile more complex than the floral one: the former was dominated by nonterpene substances, the latter was almost totally constituted by monoterpenes hydrocarbons. In addition, the main compounds were different: $(Z)$-3-hexenol acetate in the leaves, $(E)-\beta$ ocimene in the flowers; however, $\beta$-caryophyllene appeared among the common compounds 354 (Giuliani et al., Unpublished results (a), (b)).

355 Regarding the ecological role of the most abundant exclusive compounds of the floral profile, 356 they all contribute to a defensive action. In particular, germacrene D (34) develops a protective and fly-killing role (Kiran and Devi, 2007; Birkett et al., 2008); 1,8-cineole (3) shows an acaricidal (Hu et al., 2015), fumigant and larvicidal effect (Lucia et al., 2012); for 
bicyclogermacrene (37), a larvicidal activity towards Aedes aegypti L. larvae, developed through a synergistic action with germacrene $D(34)$ and $\beta$-caryophyllene (22) is reported (Dória et al., 2010). However, germacrene D (34) and 1,8-cineole (3) also exert an attractive role, together with $\beta$-caryophyllene (22) and a-humulene (29) (Cha et al., 2008; Nelson and Jackson, 2013). The major exclusive compounds of the foliar profile express a protective action. Indeed, this type of activity is ascribed to the sesquiterpene hydrocarbons, to which valencene (36) and $y$-muurolene (33) belong to (Chizzola 2013). In particular, pesticide activity is recognized in valencene derivatives (Panella et al., 2005). Referring to the ecological role of the common compounds, the promiscuous action of $\beta$-caryophyllene (22) dominates. In fact, several studies assign to this compound an attraction function towards pollinators, sometimes realized in synergy with a-humulene (29) (Abraham et al., 2018; Zhang 2018) and germacrene D (34) (Cha et al., 2008), as well as a defensive role against parasites and herbivores (Curtois et al., 2012; Köllner et al., 2013; Feng et al., 2017). Finally, alloaromadendrene (31), together with $\beta$-caryophyllene (22) and a-copaene (17), display larvicidal action (Senthilkumar et al., 2008; Costa et al., 2011). On these bases, it is possible to affirm that in S. caucasica a protective action is predominantly associated to the leaves, thanks to the dominant presence of sesquiterpene hydrocarbons in their profile. On the contrary, an attractive role is assigned to the flowers due to the exclusive and abundant percentage of germacrene $D$. Nevertheless, given the co-occurrence of $\beta$-caryophyllene in both the vegetative and reproductive emissions, both leaves and flowers act together to play a protective and attractive role. The differentiation of the volatile emission profiles based on the organ function is, indeed, reported in the literature (Ascrizzi et al, 2016). If we examine the other main chemical classes occurring in the secretory products of the glandular trichomes, previous works revealed that the presence of superficial hydrophilic secretions on plant epidermis appeared to have the function of protecting the organs against desiccation, maintaining a balanced water status, especially at early stages of expansion (Ascensão, et al., 1999; Huang et al., 2008). Considering the polyphenols, these molecules are known as powerful antioxidants and protein complexing agents (Romani et al., 2014), with this latter activity particularly expressed in plant-herbivorous interactions (Haslam, 1988). Indeed, the presence of polyphenols in plant exudates is related to the main role of increasing the resistance to herbivores, by repelling or poisoning the phytophagy (Werker, 2000).

\subsection{Conclusions}

This multidisciplinary approach represents a further step in the study of species belonging to Scutellaria genus and, overall, in the characterization of the species collected at the G. E. Ghirardi Botanic Garden (Toscolano Maderno, Lombardy, Italy), totally dedicated to medicinal plants. The set of information concerning the chemical nature of the emitted volatile substances may finally contribute to make hypothesis on the biotic interactions established by 
the examined species, thus constituting the basis for future insights on the ecological roles of the secondary metabolites.

Funding: This work was supported by the Lombardy Region, under the Call for the Enhancement of Museum Ir. 25/2016, year 2019.

Conflicts of interest: The authors declare no conflicts of interest.

\section{References}

Abraham, A.A., Verghese, A., Muthangi, S., 2018. Role of colour and volatile in foraging behaviour of honeybee Apis cerana on Jacquemontia pentanthos. J. Asia-Pac. Entomol. 21(4), 1122-1128.

Akçin, Ö.E., Özyurt, M.S., Şenel, G., 2011. Petiole anatomy of some Lamiaceae taxa. Pak. J. Bot. 43(3), 1437-1443.

Ascrizzi, R., Cioni, P.L., Giusti, G., Pistelli, L., Flamini, G., 2016. Patterns in Volatile Emission of Different Aerial Parts of Caper (Capparis spinosa L.). Chem. Biodiversity 13, 904-912.

Ascrizzi, R., Cioni, P.L., Amadei, L., Maccioni, S., Flamini, G., 2017. Geographical patterns of in vivo spontaneously emitted volatile organic compounds in Salvia species. Microchem. J. $133,13-21$.

Ascensão, L., Mota, L. and De Castro, M., 1999. Glandular trichomes on the leaves and flowers of Plectranthus ornatus: morphology, distribution and histochemistry. Ann. Bot. 84, 437447.

Bandyukova, V.A., Boikova, A., 1969. An investigation of the flavonoids of Scutellaria polyodon. I. Chem. Nat. Compd. 5(6), 513-513.

Baytop, T., 1999. Therapy with medicinal plants in Turkey, past and present. 2nd edn., Nobel Tip Kitabevleri, Istanbul, 375.

Beccari, N., Mazzi, V., 1966. Manuale di tecnica microscopica. Società Editrice Libraria, Como.

Birkett, M.A., Al Abassi, S., Kröber, T., Chamberlain, K., Hooper, A.M., Guerin, P.M., Pettersson, J., Pickett, A.J., Slade, R., Wadhams, L.J., 2008. Antiectoparasitic activity of the gum resin, gum haggar, from the East African plant, Commiphora holtziana. Phytochemistry 69(8), 1710-1715.

Bozov, P.I., Coll, J., 2015. Neo-clerodane diterpenoids from Scutellaria altissima. Nat. Prod. Commun. 10, 13-16. 
Brundrett, M.C., Kendrick, B., Peterson, C.A., 1991. Efficient lipid staining in plant material with Sudan Red 7B or Fluoral Yellow 088 in polyethylene glycol-glycerol. Biotech. Histochem. 66, 111-116.

Bruno, M., Bondi, M.L., Rosselli, S., Piozzi, F., Servettaz, O., 2000. Minor Diterpenoids from Scutellaria polyodon. J. Nat. Prod. 63(7), 1032-1034.

Çalı, İ.Ö., 2017a. Anatomical and glandular trichome characteristics of Scutellaria salviifolıa (Lamiaceae) endemic to Turkey. Int. J. Agric. Biol. 19(4), 654-658.

Cali, I.O., 2017b. Anatomy and glandular trichome micromorphology of Scutellaria orientalis L. subsp. pinnatifida Edmondtson (Lamiaceae). Bangladesh J. Bot. 3.

Cha, D.H., Nojima, S., Hesler, S.P., Zhang, A., Linn, C.E., Roelofs, W.L., Loeb, G.M., 2008. Identification and field evaluation of grape shoot volatiles attractive to female grape berry moth (Paralobesia viteana). J. Chem. Ecol. 34(9), 1180-1189.

Chizzola, R., 2013. Regular monoterpenes and sesquiterpenes (essential oils). J. Nat. Prod. 10, 978-3.

Cicek, M., Demirci, B., Yilmaz, G., Baser, K.H.C., 2011. Essential oil composition of three species of Scutellaria from Turkey. Nat. Prod. Res. 25(18), 1720-1726.

Costa, E.V., Dutra, L.M., De Jesus, H.C.R., De Lima Nogueira, P.C., De Souza Moraes, V.R., Salvador, M.J., Sócrates Cabral de Holanda Cavalcanti, Roseli La Corte dos Santos, do Nacimento Prata, A.P., 2011. Chemical composition and antioxidant, antimicrobial, and larvicidal activities of the essential oils of Annona salzmannii and A. pickelii (Annonaceae). Nat. Prod. Commun. 6(6), 1934578X1100600636.

Courtois, E.A., Baraloto, C., Paine, C.T., Petronelli, P., Blandinieres, P.A., Stien, D., Höuel, E., Bessière, J.M., Chave, J., 2012. Differences in volatile terpene composition between the bark and leaves of tropical tree species. Phytochemistry 82, 81-88.

David, R., Carde, J.P., 1964. Coloration differentielle des inclusions lipidiques et terpeniques des pseudophylles du Pin maritime au moyen du reactif NADI. C. R. Biol. 258, 1338-1340.

De La Torre, M.C., Rodríguez, B., Bruno, M., Vassallo, N., Bondì, M.L., Piozzi, F., Servettaz, O., 1997. Neoclerodane diterpenoids from Scutellaria polyodon. J. Nat. Prod. 60(12), 12291235.

De Oliveira, A.B., De Mendonça, M.S., Meira, R.M., 2013. Anatomy of vegetative organs of Scutellaria agrestis, a medicinal plant cultivated by riverine populations of the Brazilian Amazon. Rev. Bras. Farmacogn. 23(3), 386-397. 
Dereboylu, A.E., Sarikahya, N.B., Sengonca, N., Kirmizigul, S., Yasa, I., Gucel, S., Guvensen, A., 2012. Glandular trichomes morphology, chemical composition and antimicrobial activity of the essential oil of three endemic Scutellaria taxa (Lamiaceae). Asian J. Chem. 24(11), 4911-4916.

Dória, G.A., Silva, W.J., Carvalho, G.A., Alves, P.B., Cavalcanti, S.C., 2010. A study of the larvicidal activity of two Croton species from northeastern Brazil against Aedes aegypti. Pharm. Biol. 48(6), 615-620.

Feng, B., Qian, K., Du, Y.J., 2017. Floral volatiles from vigna unguiculata are olfactory and gustatory stimulants for oviposition by the bean pod borer moth Maruca vitrata. Insects $8(2), 60$.

Formisano, C., Rigano, D., Senatore, F., Arnold, N.A., Simmonds, M.S.J., Rosselli, S., Bruno, M., Loziene, K., 2013. Essential oils of three species of Scutellaria and their influence on Spodoptera littoralis. Biochem. Syst. Ecol. 48, 206-210.

Gahan, P.B., 1984. Plant Histochemistry and Cytochemistry: An Introduction. Academic Press, London.

Gao, C., Zhou, Y., Jiang, Z., Zhao, Y., Zhang, D., Cong, X., Cao, R., Li H., Tian, W., 2017. Cytotoxic and chemosensitization effects of Scutellarin from traditional Chinese herb Scutellaria altissima L. in human prostate cancer cells. Curr. Oncol. Rep. 38(3), 1491-1499.

Giuliani C., Ascrizzi R., Tani C., Bottoni M., Maleci Bini L., Flamini G., Fico G., 2017a. Salvia uliginosa Benth: glandular trichomes as bio-factories of volatiles and essential oil. Flora 233, $12-21$.

Giuliani, C., Ascrizzi, R., Corrà, S., Bini, L. M., Flamini, G., Fico, G., 2017b. Ultrastructural insight into terpene-producing trichomes and essential oil profile in Salvia greggii A. Gray. Flora 236, 107-114.

Giuliani, C., Ascrizzi, R., Lupi, D., Tassera, G., Santagostini, L., Giovanetti, M., Flamini G., Fico, G., 2018. Salvia verticillata: Linking glandular trichomes, volatiles and pollinators. Phytochemistry 155, 53-60.

Giuliani, C., Bini, L.M., 2008. Insight into the structure and chemistry of glandular trichomes of Labiatae, with emphasis on subfamily Lamioideae. Plant Syst. Evol. 276(3-4), 199.

Giuliani, C., Bottoni, M., Ascrizzi, R., Santagostini, L., Papini, A., Flamini, G., Fico, G., Unpublished results (a). Scutellaria brevibracteata subsp. subvelutina (Rech.f.) Greuter \& Burdet: morphological and phytochemical characterization. Submitted to Natural Product Research. 
Giuliani, C., Bottoni, M., Ascrizzi, R., Santagostini, L., Papini, A., Flamini, G., Fico, G., Unpublished results (b). A new study approach in the context of Open Science: the case of Scutellaria altissima L. Submitted to Plant Biology.

Greenspan, P., Mayer, E.P., Fowler, S.D., 1985. Nile red: a selective fluorescent stain for intracellular lipids droplets. J. Cell Biol. 100, 965-973.

Grzegorczyk-Karolak, I., Gołąb, K., Gburek, J., Wysokińska, H., Matkowski, A., 2016. Inhibition of advanced glycation end-product formation and antioxidant activity by extracts and polyphenols from Scutellaria alpina L. and S. altissima L. Molecules 21(6), 739.

Hallahan, D.L., 2000. Monoterpenoid biosynthesis in glandular trichomes of Labiatae plants. In: Hallahan, D.L., Gray, J.C. (Eds.), Advances in Botanical Research. Plant Trichomes. Academic Press, New York, London, 77-120.

Haslam, E., 1988. Plant polyphenols (syn. vegetable tannins) and chemical defens. A reappraisal. J. Chem. Ecol. 14(10), 1789-1805.

Hu, Z., Chen, Z., Yin, Z., Jia, R., Song, X., Li, L., Zou, Y., Liang, X., Li, L., He, C., Yin, L., Lv, C., Zhao, L., Su, G., Ye, G., Shi, F., 2015. In vitro acaricidal activity of 1, 8-cineole against Sarcoptes scabiei var. cuniculi and regulating effects on enzyme activity. Parasitol. Res. 114(8), 2959-2967.

Huang, S.S., Kirchoff, B.K. and Liao, J.P., 2008. The capitate and peltate glandular trichomes of Lavandula pinnata L. (Lamiaceae): histochemistry, ultrastructure, and secretion. J. Torrey Bot. Soc, 135, 155-167.

Irvin, L., Jackson, C., Hill, A.L., Bajaj, R., Mahmoudi, C., Brajesh, N.V., Joshee, N., 2019. Skullcaps (Scutellaria spp.): Ethnobotany and Current Research. In: Joshee N., Dhekney S., Parajuli P. (eds) Medicinal Plants. Springer, Cham. 141-168.

Jensen, W.A., 1962. Botanical histochemistry: principles and practice. WH Freeman \& Co., San Francisco.

Judd, W.S., Campbell, C.S., Kellogg, E.A., Stevens, P.F., Donoghue, M.J., 2009. Sistemática vegetal: um enfoque filogenético. Porto Alegre, Artmed Editora.

Kiran, S.R., Devi, P.S., 2007. Evaluation of mosquitocidal activity of essential oil and sesquiterpenes from leaves of Chloroxylon swietenia DC. Parasitol. Res. 101(2), 413-418.

Köllner, T.G., Lenk, C., Schnee, C., Köpke, S., Lindemann, P., Gershenzon, J., Degenhardt, J., 2013. Localization of sesquiterpene formation and emission in maize leaves after herbivore damage. BMC Plant Biol. 13, 15. 
Komarov, V.L., 1976. Flora of the U.S.S.R. Volume XX, Israel Program for Scientific Translation, 107.

Kosakowska, O., 2017. Experimental Paper. Intrapopulation variability of flavonoid content in roots of Baikal skullcap (Scutellaria baicalensis Georgi). Herba Pol. 63(1), 20-31.

Kurkcuoglu, M., Yildiz, G., Kose, Y.B., 2019. Essential oil composition of two Scutellaria from Tokat province of Turkey. J. Turkish Chem. Soc. 6(2), 115-118.

Li, B.Q., Fu, T., Dongyan, Y., Mikovits, J.A., Ruscetti, F.W., Wang, J.M., 2000. Flavonoid baicalin inhibits HIV-1 infection at the level of viral entry. Biochem. Bioph. Res. Co. 276(2), 534-538.

Li, Z.P., Wei, H.Q., 1994. Chemical compounds of the genus Scutellaria. Phytomedicine 9, 47.

Lucia, A., Juan, L.W., Zerba, E.N., Harrand, L., Marcó, M., Masuh, H.M., 2012. Validation of models to estimate the fumigant and larvicidal activity of Eucalyptus essential oils against Aedes aegypti (Diptera: Culicidae). Parasitol. Res. 110(5), 1675-1686.

Maffei, M.E., 2010. Sites of synthesis, biochemistry and functional role of plant volatiles. S. Afr. J. Bot. 76, 612-631.

Malakov, P.Y., Papanove, G.Y., 1996. A clerodanediterpenoids from Scutellaria altissima. Phytochemistry 41, 855.

Minareci, E., Pekönür, S., 2017. An Important Euroasian Genus: Scutellaria L. Int. J. Second. Metab. 4(1), 35-46.

Nelson, X.J., Jackson, R.R., 2013. Hunger-driven response by a nectar-eating jumping spider to specific phytochemicals. Chemoecology 23(3), 149-153.

Özdemir, C., Şenel, G., 2001. The morphological, anatomical and karyological properties of Salvia forskahlei L. (Lamiaceae) in Turkey. J. Econ. Taxon. Bot., 297-313.

Panella, N.A., Dolan, M.C., Karchesy, J.J., Xiong, Y., Peralta-Cruz, J., Khasawneh, M., Montenieri J.A., Maupin, G.O., 2005. Use of novel compounds for pest control: insecticidal and acaricidal activity of essential oil components from heartwood of Alaska yellow cedar. $\mathrm{J}$. Med. Entomol. 42(3), 352-358.

Paton, A., 1990. A global taxonomic investigation of Scutellaria. Kew Bull 45, 399-450.

Pool, A., 2006. New species of Scutellaria (Lamiaceae) from Mesoamerica. Novon 16, 388-403. Romani, A., Lattanzio, V., Quideau, S., 2014. Recent advances in polyphenol research. Volume 4, John Wiley \& Sons. 
Rosselli, S., Bruno, M., Simmonds, M.S.J., Senatore, F., Rigano, D., Formisano, C., 2007. Volatile constituents of Scutellaria rubicunda Hornem subsp. linnaeana (Caruel) Rech. (Lamiaceae) endemic in Sicily. Biochem. Syst. Ecol. 35, 797-800.

Senthilkumar, A., Kannathasan, K., Venkatesalu, V., 2008. Chemical constituents and larvicidal property of the essential oil of Blumea mollis (D. Don) Merr. against Culex quinquefasciatus. Parasitol. Res. 103(4), 959-962.

Shang, X., He, X., He, X., Li, M., Zhang, R., Fan, P., Zhang, Q., Jia, Z., 2010. The genus Scutellaria an ethnopharmacological and phytochemical review. J. Ethnopharmacol. 128, 279-313.

Sripathi, R., Ravi, S., 2017. Ethnopharmacology, phytoconstituents, essential oil composition and biological activities of the genus Scutellaria. J. Pharm. Sci. Res. 9(3), 275-287.

Takeoka, G.R., Dao, L., Rodriguez, D.M., Patterson, R., 2008. Headspace volatiles of Scutellaria californica A. Gray flowers. J. Essent. Oil Res. 20(2), 169-171.

Takeoka, G.R., Rodriguez, D.M., Dao, L., Patterson, R., 2009. Headspace volatiles of Scutellaria baicalensis Georgi flowers. J. Essent. Oil Bear. PI. 12(4), 435-442.

Werker, E., 2000. Trichome diversity and development. In: Hallahan, D.L., Gray, J.C.(Eds.), Advances in Botanical Research. Plant Trichomes. Academic Press, NewYork London, 1-35.

Werker, E., 2006. Function of essential oil-secreting glandular hairs in aromatic plants of Lamiaceae a review. Flavour Frag. J. 8(5), 249-255.

Yilmaz, G., Ciçek, M., Demirci, B., Başer, H.C., 2019. Essential oil compositions of subspecies of Scutellaria brevibracteata Stapf from Turkey. J. Essent. Oil Res. 31(4), 255-262.

Zhang, X.M., 2018. Floral volatile sesquiterpenes of Elsholtzia rugulosa (Lamiaceae) selectively attract Asian honey bees. J. Appl. Entomol. 142(3), 359-362. 
Figure 1.
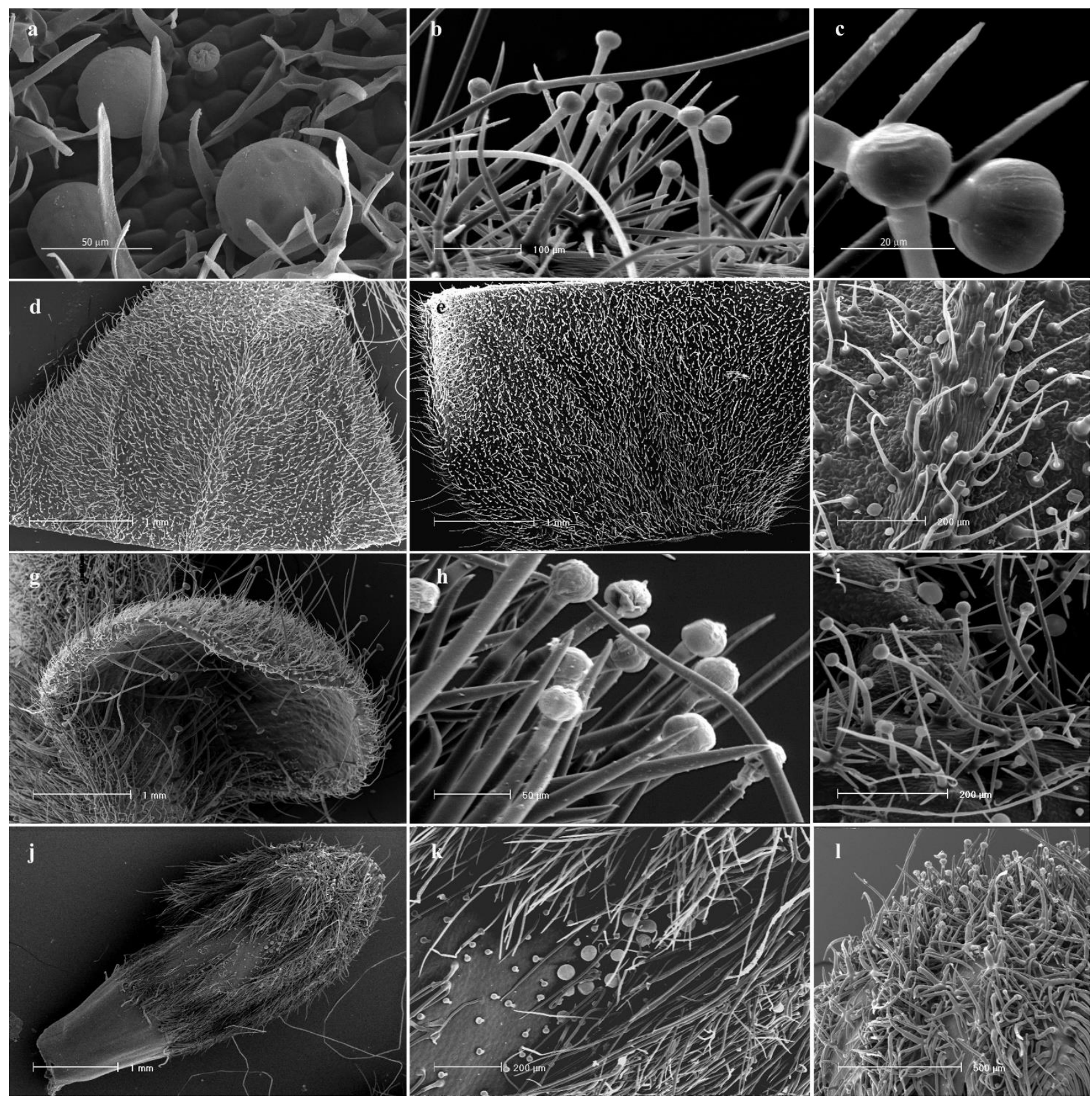
$600 \quad$ Figure 2.
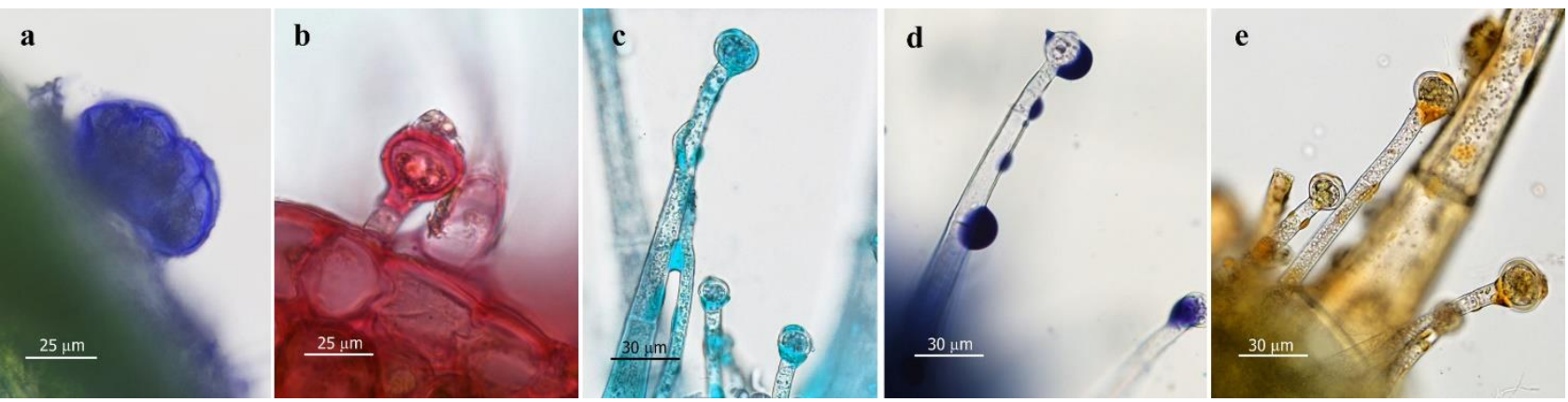

602

603

604

605

606

607

608

609

610

611

612

613

614

615

616

617

618

619

620

621

622

623

624

625

626

627 
628 Table 1. Distribution pattern of the glandular trichomes in Scutellaria caucasica A. Ham.

\begin{tabular}{lcccccccccc}
\hline \multirow{2}{*}{ Trichome type } & \multirow{2}{*}{ Stem } & \multicolumn{2}{c}{ Leaf } & \multicolumn{2}{c}{ Bract } & \multicolumn{2}{c}{ Calyx } & \multicolumn{2}{c}{ Corolla } \\
& & adax & abax & adax & abax & adax & abax & adax & abax \\
\hline peltate & \pm & + & + & - & + & - & + & - & + \\
short capitate & + & + & ++ & + & + & + & + & + & ++ \\
long capitate & - & - & - & - & + & - & + & - & + \\
\hline Symbols: (-) missing, ( \pm ) sporadic, (+) present, (++) abundant & & & &
\end{tabular}

629

630

631

632

633

634

635

636

637

638

639

640

641

642

643

644

645

646

647

648

649

650

651

652

653

654

655

656

657 
658 Table 2. Results of the histochemical tests on the glandular trichomes in Scutellaria caucasica 659 A. Ham.

\begin{tabular}{llccc}
\hline Stainings & Target-compounds & peltate & $\begin{array}{c}\text { short } \\
\text { capitate }\end{array}$ & $\begin{array}{c}\text { long } \\
\text { capitate }\end{array}$ \\
\hline Fluoral yellow-088 & Total lipids & + & - & + \\
Nile Red & Neutral lipids & + & - & + \\
Nadi reagent & Terpenoids & ++ & - & + \\
Ruthenium Red & Acid polysaccharides & - & + & + \\
Alcian Blue & Muco-polysaccharides & - & - & ++ \\
Ferric Tricholoride & Polyphenols & - & - & + \\
\hline
\end{tabular}


Table 3. HS-SPME profiles of the leaves and flowers of Scutellaria caucasica A. Ham.

\begin{tabular}{|c|c|c|c|c|}
\hline & \multirow{2}{*}{ I.r.i. ${ }^{a}$} & \multirow{2}{*}{ Compounds } & \multicolumn{2}{|c|}{ Relative Abundance (\%) } \\
\hline & & & Leaves & Flowers \\
\hline 1 & 993 & myrcene & $-b$ & 0.33 \\
\hline 2 & 1032 & limonene & - & $\operatorname{tr}^{\mathrm{c}}$ \\
\hline 3 & 1034 & 1,8-cineole & - & 8.00 \\
\hline 4 & 1052 & $(E)$ - $\beta$-ocimene & - & 1.49 \\
\hline 5 & 1140 & nopinone & - & 0.15 \\
\hline 6 & 1143 & camphor & - & 0.12 \\
\hline 7 & 1178 & 4-terpineol & - & 0.56 \\
\hline 8 & 1187 & (Z)-3-hexenyl-butyrate & - & 0.43 \\
\hline 9 & 1204 & decanal & - & 0.15 \\
\hline 10 & 1241 & methyl carvacrol & - & 1.40 \\
\hline 11 & 1259 & linalool acetate & - & 0.16 \\
\hline 12 & 1340 & $\delta$-elemene & 0.24 & 0.59 \\
\hline 13 & 1351 & a-cubebene & 0.27 & 0.24 \\
\hline 14 & 1368 & cyclosativene & 0.13 & - \\
\hline 15 & 1372 & a-ylangene & $\operatorname{tr}$ & - \\
\hline 16 & 1373 & longicyclene & - & 0.14 \\
\hline 17 & 1376 & a-copaene & 2.10 & 2.72 \\
\hline 18 & 1384 & $\beta$-bourbonene & 0.83 & 0.72 \\
\hline 19 & 1390 & $\beta$-cubebene & 1.28 & 0.66 \\
\hline 20 & 1410 & a-gurjunene & 0.42 & 0.19 \\
\hline 21 & 1416 & cis-a-bergamotene & 0.37 & $\operatorname{tr}$ \\
\hline 22 & 1420 & $\beta$-caryophyllene & 34.12 & 34.97 \\
\hline 23 & 1429 & $\beta$-copaene & 2.17 & 1.52 \\
\hline 24 & 1432 & $\beta$-gurjunene & 0.40 & 0.48 \\
\hline 25 & 1439 & a-guaiene & - & 0.47 \\
\hline 26 & 1441 & aromadendrene & 0.60 & - \\
\hline 27 & 1447 & cis-muurola-3,5-diene & 0.20 & 0.16 \\
\hline 28 & 1454 & trans-muurola-3,5-diene & 0.11 & - \\
\hline 29 & 1456 & a-humulene & 3.01 & 3.08 \\
\hline 30 & 1460 & sesquisabinene & - & $\operatorname{tr}$ \\
\hline 31 & 1461 & alloaromadendrene & 2.43 & 1.04 \\
\hline 32 & 1462 & cis-muurola-4(14),5-diene & 1.31 & 0.91 \\
\hline 33 & 1477 & $\mathrm{y}$-muurolene & 42.57 & 0.65 \\
\hline 34 & 1482 & germacrene D & - & 31.65 \\
\hline 35 & 1491 & trans-muurola-4(14),5-diene & 0.38 & 0.33 \\
\hline 36 & 1492 & valencene & 1.82 & - \\
\hline 37 & 1495 & bicyclogermacrene & - & 2.89 \\
\hline 38 & 1498 & a-muurolene & 0.45 & 0.44 \\
\hline 39 & 1507 & $(E, E)$-a-farnesene & 1.04 & 1.52 \\
\hline 40 & 1513 & trans- $\gamma$-cadinene & 0.86 & 0.61 \\
\hline 41 & 1524 & $\delta$-cadinene & 1.11 & 1.03 \\
\hline 42 & 1534 & cadina-1,4-diene & 0.25 & - \\
\hline 43 & 1538 & a-cadinene & 0.29 & 0.18 \\
\hline 44 & 1575 & germacrene D-4-ol & 0.64 & - \\
\hline \multirow[t]{7}{*}{45} & 1581 & caryophyllene oxide & 0.26 & - \\
\hline & & Monoterpene hydrocarbons & - & 1.82 \\
\hline & & Oxygenated monoterpenes & - & 10.39 \\
\hline & & Sesquiterpene hydrocarbons & 98.76 & 87.19 \\
\hline & & Oxygenated sesquiterpenes & 0.90 & - \\
\hline & & Non-terpenes derivatives & - & 0.58 \\
\hline & & Total & $99.66 \%$ & $99.98 \%$ \\
\hline
\end{tabular}

${ }^{a}$ Linear retention indices on a DB-5 capillary column; ${ }^{b}$ Not detected; ${ }^{c}$ Traces, $<0.1 \%$. 
693 Figure 1. SEM micrographs showing distribution and types of trichomes of Scutellaria 694 caucasica A. Ham. (a). Peltate and short-stalked capitate trichomes. (b) Long-stalked capitate 695 trichomes. (c) Particular of the multicellular head of the long-stalked capitate trichome. (d, e) 696 Leaf abaxial (d) and adaxial (e) surfaces with simple non-glandular hairs, peltate and short697 stalked capitate trichomes. (f) Particular of the leaf abaxial surface with peltate, short-capitate 698 and simple non-glandular trichomes. (g) Particular of the calyx at the skullcup. (h) Details the 699 Iong capitates; notice the secreted material on the head surfaces. (i) Particular of the calyx 700 abaxial surface exhibiting scanty peltates, short capitates and abundant long capitates. (j) 701 General view of a floral bud. (k) Particular of the corolla abaxial surface at the median region 702 with abundant long simple trichomes, peltates and short capitates. (I) Particular of the corolla 703 abaxial surface at the distal region with abundant long simple trichomes and long capitates.

704 Figure 2. Histochemistry of the glandular trichomes of the vegetative and reproductive organs 705 of Scutellaria caucasica A. Ham. (a) Peltate trichome: Nadi reagent. (b) Short-stalked capitate 706 trichome: Ruthenium Red. (c-e) Long-stalked capitate trichomes: capitate Trichome: Alcian 707 Blue (c), Nadi reagent (d), $\mathrm{FeCl}_{3}(\mathrm{e})$. 